\title{
Anotar a Adília Lopes: entre traducción, poesía y gestión editorial
}

\section{Alejandro Giraldo Gil \\ Universidad de los Andes}

Resumen: Adília Lopes, que aparenta ser una poeta de la ingenuidad, de la poesía sencilla y cotidiana, es en realidad una poeta de la referencia y la complejidad. Su poesía se deja leer como una poesía breve y fácil de experiencias cotidianas, pero esto es un velo. En realidad, en la sencillez de su poesía se esconde una red de referencias, reflexiones, argumentos, aproximaciones y adaptaciones al canon literario, al filosófico, al cultural pop, ya el cultural erudito. Este trabajo quiere demostrar la necesidad de leer la poesía adiliana acompañada por anotaciones juiciosas y exhaustivas que develen estos referentes. $Y$, con esto, hablar de la necesidad de anotar a Adília Lopes.

Palabras clave: Adília Lopes, anotación, referentes, traducción, figura retórica, tejido textual

\begin{abstract}
Adília Lopes, who is seemingly a poet of naivety, whose poetry is simple and of everyday life, in reality is a poet of complexity and erudite references. Her poetry can be read as a brief and easy reading of ordinary experiences, but this is just a veil. Actually, in the simplicity of her poetry lies a deep web of complex references, reflections, arguments, approaches and adaptations to both the literary, philosophical canons, and to pop culture and "high" culture. This work aims to demonstrate the necessity of reading adilian poetry through thorough and exhaustive annotated editions that allow her reader to delve into these references. In this, this work also aims to talk about the necessity of annotating the works of Adília Lopes.
\end{abstract}

Keywords: Adília Lopes, annotation, referents, translation, rhetorical figure, textual weaving 


\section{Introducción: Adília Lopes y una erudición pop}

Adília Lopes, nombre literario que asume María José da Silva Viana Fidalgo de Oliveira (Lisboa, 1960), es quizá la poeta lisboeta contemporánea más emblemática en las últimas décadas de poesía portuguesa. Sin embargo, por la sencillez de su escritura que en años recientes ha tomado un giro hacia la brevedad formal y la cotidianidad de casa, tal vez sea muy común que las primeras lecturas de Adília engañen a un lector desprevenido y lo dejen con la sensación de haber leído un verso libre simple, destartalado, quizá en exceso y crudamente autobiográfico, demasiado cotidiano. Y será por eso por lo que la crítica no fue generosa con ella en sus primeros años de publicación. Sin embargo, después de hacer una segunda lectura más atenta, el lector devela con certeza referencias interminables a la cultura pop, a la historia del arte, a la filosofía, a la teoría literaria y a los cánones literarios universal y portugués. Por eso, entre varios otros sucesos, y no mucho después de una crítica poco dispuesta, Adília Lopes se abrió campo entre académicos y lectores atentos que vieron en su poesía no sólo cuestiones anecdóticas y cotidianas sino, también, el potencial crítico que se escondía entre sus líneas.

Hoy son varios los críticos que reconocen la potencia que se esconde en la poética adiliana: Rosa Maria Martelo, Burghard Baltrusch, Paulo de Medeiros, António Ladeira, Ana Klobucka y Ellen Sapega, por nombrar a algunos. En la mayoría de ellos, si no en todos, hay un reconocimiento doble: la obra de Adília Lopes habla, sí, desde lo cotidiano, los referentes culturales del día a día, y sobre ella misma y sobre su vida (que no se ha caracterizado por ser fácil). Y también habla desde la cultura popular. Pero dentro de esos referentes, que podríamos llamar más "ligeros", y que ella imbrica en su escritura con una cotidianidad desgarradora, Adília esconde referentes letrados que le permiten hacer fuertes reflexiones éticas, morales y filosóficas. En su artículo "Adília Lopes: traducir entre la entropía y la subversión", Burghard Baltrusch afirma que la obra poética de Adília

[...] coquetea de una forma intencional y subversiva con características del pop, con elementos kitsch, con la trivialidad, con el lenguaje coloquial y popular, con el chismorreo de la hora del té y de los programas rosa, con la moralidad decimonónica para chicas en las novelas de la Comtesse de Ségur, pero también juega de una forma polisémica con las ciencias, con una intertextualidad muy erudita y 
burguesa, con el hibridismo discursivo y diastrático, con lo repetitivo y tautológico, con la citación y la traducción, con la parodia y la ironía - también de sí misma - (Baltrusch 2008: 234)

Con esto, lo que Baltrusch nos está sugiriendo justamente es que la poética adiliana se constituye como un tejido de referentes eruditos, para usar su término, así como de referentes cotidianos (culturales y biográficos). Rosa Maria Martelo hará una afirmación similar en su ponencia "El guante y la mano (una historia de salvación)", y a propósito de una reflexión que hace sobre las formas de creación posmodernas de Marjorie Perlorff. Allí, Martelo afirmó que

Adília Lopes es, sin lugar a dudas, [...] una autora en la que el proceso de citación y collage produjo una notable novedad poética y una innegable eficacia al nivel de la crítica de la sociedad de consumo y del productivismo neoliberal. La obra de Adília Lopes se asienta en una prodigiosa memoria verbal, trabaja una especie de archivo de curiosidades discursivas, desde las más eruditas hasta las más populares y familiares (Martelo 2019: 2)

Cabe repetir con esto que la poética de Adília, concuerda también Martelo, se teje siempre desde un archivo de referencias múltiples: eruditas, cotidianas. Y con este reconocimiento, en su texto Martelo hace más adelante otro que es crucial para entender la manera en la que la poética adiliana se constituye a sí misma: esta imbricación de referentes eruditos y cotidianos sucede y se media en la figura que la poetisa misma construye de sí. Es decir, la figura de "Adília Lopes" es el punto vinculante y catalítico entre Maria José, la escritora, y su "archivo de curiosidades discursivas" que dan como resultado una obra poética particular, a la vez pop, a la vez cursi, a la vez intelectualmente punzante, a la vez agitadora. Como afirma Baltrusch, una obra poética Kitsch.

Ana Bela Almeida, en su libro Adília Lopes (2016), le reconoce a la poetisa justamente un ímpetu agitador cuando se usa a sí misma en su poesía como mecanismo de denuncia y crítica. Al respecto del poema "[Eu quero foder foder | achadamente]" del poemario Versos verdes (1999), Almeida sitúa los versos en el contexto político de un Portugal que vive unos años después del 25 de abril de 1974, es decir, que vive después de la dictadura. Citando el poema en cuestión, y recordando el rechazo que tuvieron las Novas cartas portuguesas, publicadas tan cerca del fin de la dictadura, Almeida afirma que "Poderíamos alegar que, 
pelo meio, se deu a Revolução dos Cravos que os versos citados parodiam e, com esta, uma suposta liberalização da vida intelectual portuguesa, mas a obra de Adília Lopes constitui, em boa parte, um esforço continuado por mostrar, precisamente, que esta 'não é revolução nenhuma'” (Almeida 2016: 11). Cito aquí los versos del poema a los que se refiere Almeida:

\author{
Yo quiero follar follar \\ halladamente \\ si esta revolución \\ no me deja \\ follar hasta morir \\ es porque \\ no es revolución \\ alguna (Lopes 2018: 129) ${ }^{1}$
}

Y es que Adília Lopes, así como es figura autoral, es también figura retórica de su propia poesía: se usará constantemente como objeto y sujeto de crítica y reflexión poética: si ella no puede follar hasta morir, la revolución no tuvo sentido. Éste es un reconocimiento que hacen ambas, Martelo y Almeida sobre Adília como su propia figura retórica. Este recurso nace de una relación que existe entre Maria José y su nombre literario, Adília Lopes. En dos ocasiones, Martelo ha propuesto que la relación que existe entre ambas es 1 . un “contrato autobiográfico" y, 2. también, una relación dónde Adilia Lopes es una suerte de "guante transparente" — de piel translúcida— que recubre, a la vez que expone, a María José. Estos dos conceptos aparecen, el primero, en su artículo "As armas desarmantes de Adília Lopes" y, el segundo, en la ponencia que ya he mencionado antes. Hablaré de esta relación en detalle más adelante.

Estos reconocimientos que hacen las académicas mencionadas no son gratuitos: una primera lectura de la poesía de Adília no basta porque, como ya he dicho, una lectura desatenta deja al lector con la impresión de no haber leído nada verdaderamente impactante, como bien sugiere Almeida que fue lo que le sucedió a la primera crítica que leyó a Adília (Almeida 2016: 13-14). Y es porque, insisto, se necesita una (segunda) lectura con ojos escudriñadores y, quizás, académicos, para poder descobijar el potencial que se esconde detrás del nombre "Adília Lopes" y la poesía que firma. 
Adília no es, nunca lo ha sido, una escritora de la inocencia básica o simple. Adília sería, más bien, la escritora (o la figura-de-escritora) pícara que, a modo de brincadeira, esconde entre sus poemas referentes, críticas, teoría y reflexiones. No en vano, el primer título de su poemario Versos verdes, del que Almeida extrae el poema que he citado, fue, en realidad, Florbela Espanca espanca, jugando con el nombre de otra de las poetas emblemáticas del siglo XX portugués. Y, por la misma línea, en 2016 publica un libro con un título alusivo a uno de los teóricos emblemáticos de la teoría literaria de la segunda mitad del siglo XX: Z/S.

Este poemario es, quizá felizmente, muy representativo de la imbricación de lo pop y lo erudito en Adília. No sólo está dedicado a Roland Barthes, autor de S/Z (1970), sino que además está desbordado por referencias e intertextos en forma de adaptaciones poéticas, reflexiones éticas, críticas literarias, comparaciones cinematográficas y de la historia del arte, y burlas y bromas de sí misma (y de sus médicos) entre anécdotas y recuerdos de sus días. Verlas, no obstante, requiere de un lector que haga un trabajo de lectura largo y juicioso o, mejor, que haga un trabajo a la manera barthiana, es decir con un "archivo de curiosidades discursivas" capaz de dialogar con aquél (inmenso) de Adília Lopes.

$Y$ ese fue el trabajo que tuvo que hacerse para proponer dos traducciones al español de Adília Lopes. El primer trabajo, una antología publicada en el 2018 y que lleva por título Escribir un poema es como atrapar un pez, y el segundo, una traducción completa del poemario barthiano, es decir, Z/S, que saldrá publicada en 2020. Para poder dar a luz estas dos traducciones, hubo que hacer una lectura cuidadosa de la poética adiliana que pidió ser descifrada en ambas claves: la erudita y la cotidiana. Como resultado, ambas traducciones se vieron "ensuciadas" por un aparato de anotación que tuvo como función volver transparente el tejido discursivo del que están hechos los poemas, no sólo en cuestiones de lenguaje y traducción, sino también de referentes culturales (tanto de alta cultura como de cultura popular), académicos, anecdóticos, etc. Este es un texto que quiere reflexionar sobre cómo, por el poder que tiene la figura poética de Adília Lopes, esas traducciones tuvieron que verse acompañadas de anotaciones. 


\section{Parte I: anotar a Adília Lopes}

Parecería extraño sugerir que a un poeta contemporáneo deba anotársele, pues este recurso editorial (la anotación) está reservado para textos clásicos, para los cánones literarios 0 , al menos, para textos y escritores con los que se tiene alguna distancia léxicotemporal. Y, en efecto, quizá una gran parte de las reflexiones alrededor de la anotación y las ediciones críticas están hechas con ejemplos canónicos o, al menos, ejemplos con un siglo de distancia entre el crítico y el texto. Y sin embargo, en noviembre del 2018, la editorial colombiana Tragaluz editores publicó una antología comprensiva de Adília Lopes que viene, aunque no excesivamente, anotada. ${ }^{2}$ Muy en sintonía con el espíritu de las ediciones críticas anotadas, aunque guardando alguna distancia respetuosa con ellas, Escribir un poema es como atrapar un pez no sólo cumple con la función de traer a Adília Lopes al mundo hispanoparlante, sino también de crear puentes entre el universo adiliano y sus potenciales lectores de habla hispana. Y llega a este mundo hispanoparlante con notas, precisamente porque el universo adiliano es una red compleja de referencias (entre culturales, pop y eruditas) que se disfraza de simpleza. No obstante, y quizá porque las fuerzas editoriales de Tragaluz lucharon por un balance entre anotación y texto de corrido, del compendio original que entregué a la editorial tuve que archivar muchas de las notas que acompañaron la primera versión de la antología (salvo, quizás, por dos o tres notas extensas que logré mantener en la edición final).

Ese primer ejercicio de anotación, que sucedió de manera espontánea cuando traduje por primera vez a Adília, luego me habría dado las herramientas para enfrentarme a otro texto quizá más complejo de Adília: Z/S. En un segundo ejercicio de traducción adiliana, y ahora con la tarea consciente de develar lo más que pudiera las profundidades discursivas, léxicas y culturales del universo adiliano contenido en este poemario del 2016, me entregué al oficio de la investigación y la anotación de casi todos los poemas que componen el libro. Acompañada de un aparato teórico (un poco del cuál se puede leer en la siguiente sección), la traducción que propongo de $Z / S$ tiene como fin develar, a través de dos tipos de notas notas a la traducción y notas contextuales-, el tejido referencial que compone este poemario de Adília y, quizá también, a Adília misma como locus de escritura. En unos párrafos más adelante hablo un poco más de este sistema. 
¿Por qué presentar una traducción anotada de una poeta contemporánea? La primera respuesta, casi evidente y fácil, es porque, justamente, es una traducción. Eso supone un primer nivel de distanciamiento: yo y mi lector ideal hablamos español mientras que Adília escribe en portugués de Portugal, y yo como traductor de ese portugués tengo que negociar ciertos obstáculos que hay cuando paso el texto de un lado de lenguaje al otro. Y, a pesar de que entre el español y el portugués no hay una distancia monumental, sí existen diferencias semánticas importantes que requieren de esta negociación que hago yo como traductor.

En esta negociación, en estos procesos de construcción de puentes, siempre suceden cosas que vale la pena dejar registradas: decisiones sobre cómo traducir una expresión o un dicho, diferencias que existen entre el significado de una misma palabra entre los dos idiomas, juegos lingüísticos que se hacen en una lengua y que se pasaron a otra de una manera diferente (o no), dobles significados que se pierden y que hay que rescatar, etc. $Y$, de esta naturaleza son el primer grupo de notas que acompañan la edición que propongo: notas sobre la traducción. En ese sentido, cabe inferir que esa naturaleza de ese primer grupo de notas se concentraría, entonces, en cuestiones meramente anecdóticas de la experiencia del traductor de $Z / S$. Sin embargo, como Adília Lopes es su propio locus de escritura, la consciencia de lenguaje que se requiere para traducirla complicaría de cierta manera la cuestión "meramente anecdótica"; las anotaciones sobre la traducción requerirían algo más allá de una mera reflexión filológica o, mejor, requerirían acompañar el ejercicio filológico de un ejercicio hermenéutico. $Y$, en ese sentido, surgió de allí una necesidad de conectar este primer grupo de notas con el segundo: las notas intertextuales, o aquellas encargadas de develar el tejido referencial de la poética adiliana (ver fig. 1 y fig. 2).

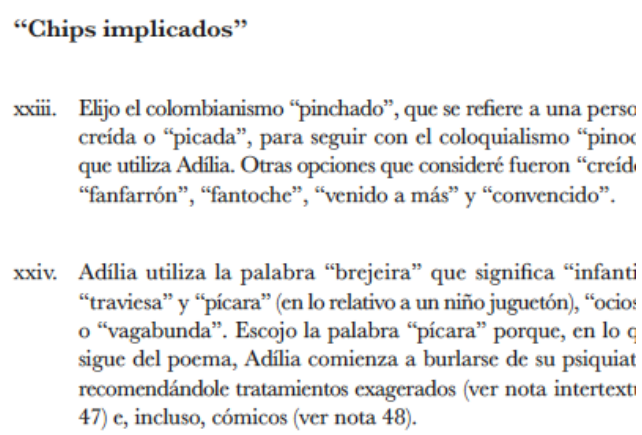

Figura 1: notas a la traducción Poema "Chips implicados", $Z / S$ 


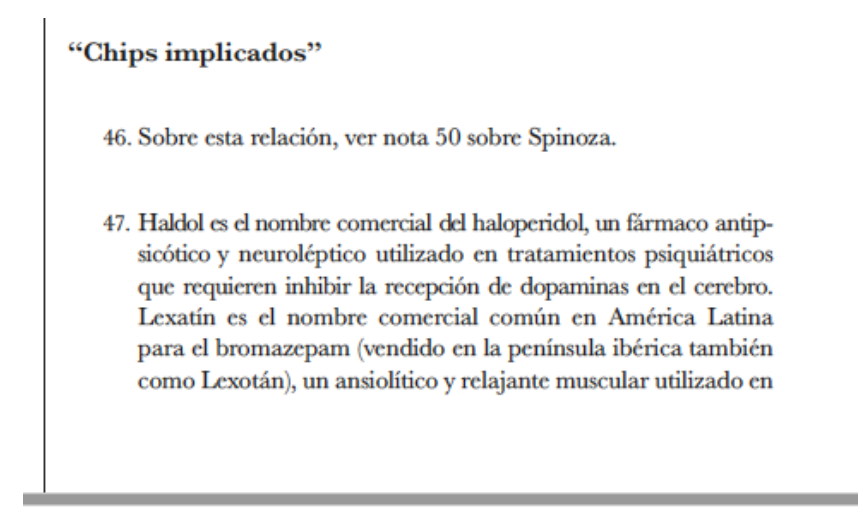

Notas intertextuales

medicina para tratar estrés y ansiedad clínica, dolores severos y, en ocasiones, como sedante. La dosis acostumbrada está entre los $1,5 \mathrm{mg}$ y los $6 \mathrm{mg}$, lo que hace que la dosis sugerida por Adília (12mg) sea exageradamente alta.

48. Adília se refiere a un episodio protagonizado por el exjugador portugués de fútbol, Paulo Futre, quien en 2014 realizó un anuncio televisivo de Libidum Fast, un estimulante sexual masculino de la compañía Bliss Nature. El comercial no fue aprobado por las autoridades para circular en televisión, aunque eso no detuvo a la compañía y al mismo Futre de publicarlo en redes sociales. Según un artículo publicado por ESPN Brasil, en tres días, el video obtuvo más de 178 mil reproducciones en la plataforma YouTube, y más de mil likes en la página de Facebook del jugador.

Figura 2: notas intertextuales

Poema "Chips implicados", $Z / S$

Como Adília es, insisto, su propio locus de escritura, de configuración y reconfiguración discursiva, hay en su gesto escritural cuestiones que trascienden las preocupaciones filológicas de su lenguaje: mediante la escritura, que funcionaría como un hilo y aguja, Adília teje en sus poemas su "archivo de curiosidades discursivas" (que yo compararía con la "biblioteca interminable de citas" de la que habla Roland Barthes en "La muerte del autor"). Esto significa que su traductor debe no sólo tener en cuenta cuestiones de lenguaje formal sino también, en el ejercicio de la traducción, lograr darse cuenta de los juegos retóricos y hermenéuticos con los que Adília constituye su universo poético y, así, anotarlos. Para repetirme, al ejercicio filológico de la traducción tendría que acompañárselo también con uno hermenéutico y, por ello, surgen las notas intertextuales. Por ello, también, 
ambas tipologías de anotación dialogan la una con la otra, como se puede ver en las figuras 1 y 2.

El poema del que extraigo estas notas es "Chips implicados" de $Z / S$, un poema en prosa en el que Adília Lopes, escribiendo desde una "verdad poética propia", ${ }^{3}$ reflexiona sobre la composición química y espiritual de su cabeza y de aquella de sus terapeutas. En cuestiones anecdóticas, la nota xxiii explica por qué la palabra "pinoca" queda traducida como "pinchado", así como la nota xxiv explica por qué "brejeira" queda como "pícara". Esta segunda nota a la traducción, sin embargo, invita al lector a leer las notas intertextuales 47 y 48 y, necesariamente, a leer las demás notas intertextuales que acompañan al poema. Y aquí es donde comienzan los sucesos verdaderamente interesantes: las notas intertextuales no sólo se referencian con las notas a la traducción, sino también se referencian entre ellas mismas. Y, así mismo, en esa referenciación cruzada es donde comienza a develarse el tejido referencial de Adília Lopes: las notas intertextuales, en este caso de "Chips implicados", e igual las demás notas del poemario, invitan a leerse las unas con las otras. La nota 46 pide que se lea la 50 (fig. 3) que, a su vez, ofrece un poco de contexto filosófico sobre los juegos que hace Adília Lopes cuando habla en el poema del perro de Spinoza, y juega anagramáticamente con las palabras "Dog" y "God" (Lopes 2016: 75) atando, así, las referencias eruditas del poema con una reflexión ética y filosófica. La última nota intertextual del poema, la 51 (fig. 4), habla sobre el neurotransmisor y, con ello, haría la última conexión entre las notas 46 a 50. Quedarían, así, develados los juegos que Adília entreteje en su aparentemente inocente burla de los antidepresivos, los ansiolíticos y los terapeutas que se los recetan: a Adília no la cura la terapia, pues sus terapeutas estarían más chiflados que ella. A Adília la cura la filosofía de Spinoza, la comprensión de que todo el mundo es, incluida ella y su cabeza maltrecha, un aspecto de Dios.

50. Baruch Spinoza (1632-1677) fue un pensador neerlandés de origen sefardi, considerado (aunque póstumamente y de manera tardía) como uno de los tres racionalistas de la filosofia junto con René Descartes (1596-1650) y Gottfried Leibniz (16461716). A propósito de este poema, Spinoza propuso una teoría metafisica en la que juntaba las tres substancias cartesianas - la res cogitans (el pensamiento), la res extensa (extensión) y Dios - en una sola substancia. Dicha substancia, en cuentas demasiado resumidas, significaría que dios y el cosmos no son entidades separadas (la segunda producto de la primera) sino una y la misma. Por ende, un perro sería por sí un aspecto de Dios, parte de la substancia única que es Dios. De allí que Adilia, además de mencionar a Dios y a Spinoza, haga un

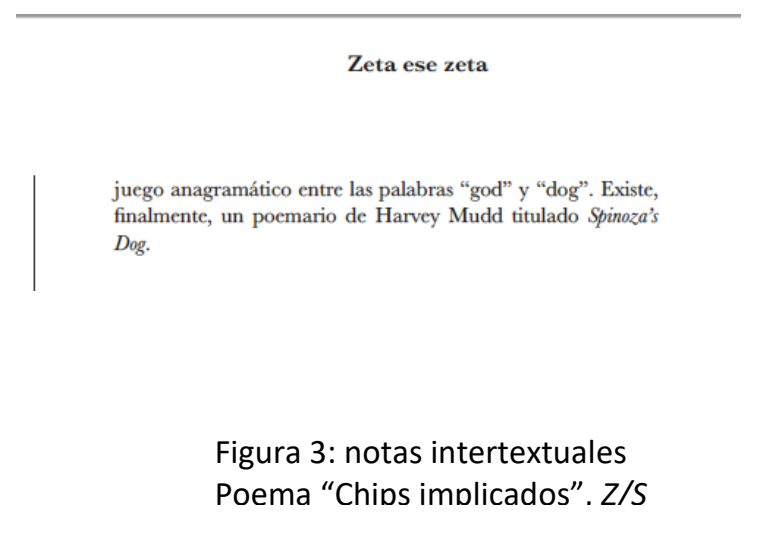


51. El neurotransmisor es la biomolécula, o mejor decir los "chips implicados" en la transmisión de información entre neuronas, proceso que resulta afectado (positiva o negativamente) por tratamientos como el Haldol y el Lexatín. En efecto, Spinoza no escribió nada sobre neurotransmisión. Adília sugiere, no obstante, que es su comprensión de la substancia única de Spinoza lo que la salva de la locura, a pesar de estar ya un poco "a cinco estrellas, siete estrellas", debido al "rocambole" psiquiátrico -psicoanalítico al que se ha sometido durante varios años.

Figura 4: notas intertextuales

Poema "Chips implicados", Z/S

Y aún quiero traer otro ejemplo a colación, uno que quizá ejemplifique mejor los tejidos textuales que suceden en el poemario y, a mi parecer, son representativos de la poética general adiliana: las notas que acompañan la traducción del poema "Nihil Novum" (fig. 5), de Florbela Espanca (y que Adília utiliza como epígrafe en su poemario), y las notas intertextuales que acompañan el poema "Ser poeta" (fig. 6). La primera nota, que se ocupa de las diferencias en método para la traducción de Espanca y la traducción de Adília, da también pistas sobre la composición de otro poema de Espanca que aparece reescrito por Adília. Ese poema es, justamente, "Ser poeta". Por ende, mi decisión de dejar la palabra "charneca", que se refiere a una zona desértica o un arenero en español (y que poéticamente podría haberse traducido como "arena"), no sólo responde a una cuestión filológica de dejar traspasar el portugués sino también porque es en el poemario Charneca em flor de Espanca donde está la versión original del poema que Adília reescribe en Z/S, es decir, "Ser poeta". El poema original de Espanca, publicado en Charneca em flor es "Perdidamente". A esta acción de reescritura yo, en las notas, la llamo "calcar", que es un término que le robo a la misma Adília de otro poema: "Decalcado de um poema de Jorge Sousa Braga de que gosto muito", en el que Adília realiza la misma acción de reescritura, pero esta vez con el poema "Sermão da montanha" de Sousa Braga. La nota 29, a la que la nota ix hace referencia, explica justamente cómo es ese proceso de "calco" poético que hace Adília del poema original de Espanca. ${ }^{4} \mathrm{Y}$, felizmente, la nota también referencia a otro poema del que ya había hablado en la introducción: "[Yo quiero follar, follar]", que se 
publicó en Versos verdes (otrora Florbela Espanca espanca), y del que existe una tercera nota que acompañó a dicho poema en la antología Escribir un poema (fig 7.) que versa sobre la traducción de la palabra "achadamente" - una invensión adiliana - por "halladamente", y que apunta a la última estrofa del ya citado poema "Perdidamente" de Espanca.

"Nihil Novum"

ix. Nihil Novum es un soneto de Florbela Espanca publicado en el poemario Reliquiae (1934). Sobre esta traducción en particular, habría que notar que, en método, difiere del resto del poemario.

Notas a la traducción

\begin{abstract}
El verso libre adiliano permite cierta libertad a la hora de escoger palabras y buscar equivalencias lingüísticas entre los sociolectos del traductor y la poetisa. No así con este soneto de Espanca, escrito con rima -a, b, b, a/c, d, d, c/e, f, g/e, f, $\mathrm{g}-$, aunque con una métrica flexible (cada verso en portugués cuenta con entre 10 y 14 silabas, que no se repiten en un orden determinado en cada estrofa). Para traducir este soneto, había que respetar la rima tanto como el significado de cada verso y, en el caso de la rima del primer verso de la tercera y la cuarta estrofa, hubo que reemplazar la ciudad de Ispahán, "Ispaã" por Bengal (Bengala, según una de las pronunciaciones bengalíes y, de ahí, la escritura inglesa) para que rimara con "vã", banal (o vana), y mantener, de todas formas, la temática orientalista del poema. Decidí, también, dejar la palabra original "charneca", en lugar de "arena", que hace referencia, además, a otro libro de Espanca, Charneca em Flor (1931) y del que Adilia extrae y reescribe, o "calca" en palabras suyas, el poema "Ser poeta" (ver notas intertextuales 21 y 29).
\end{abstract}

Figura 5: notas a la traducción

Epígrafe "Nihil Novum", Z/S 


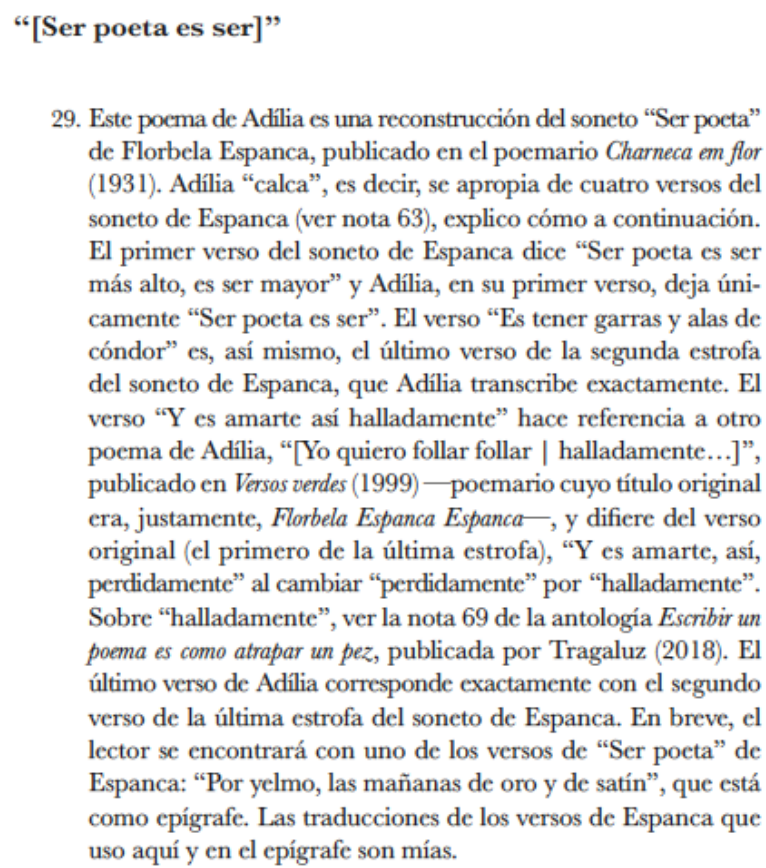
poema de Adilia, "[Yo quiero follar follar | halladamente...]", publicado en Versos verdes (1999) — poemario cuyo título original era, justamente, Florbela Espanca Espanca-, y difiere del verso original (el primero de la última estrofa), "Y es amarte, así, perdidamente" al cambiar "perdidamente" por "halladamente". Sobre "halladamente", ver la nota 69 de la antología Escribir un poema es como atrapar un pez, publicada por Tragaluz (2018). El último verso de Adilia corresponde exactamente con el segundo verso de la última estrofa del soneto de Espanca. En breve, el lector se encontrará con uno de los versos de "Ser poeta" de Espanca: "Por yelmo, las mañanas de oro y de satín", que está como epígrafe. Las traducciones de los versos de Espanca que uso aquí y en el epígrafe son mías.

Figura 6: notas intertextuales

Poema "Ser poeta", $\mathrm{Z} / \mathrm{S}$

Con esto, lo que quiero mostrar es cómo Adília logra, con un epígrafe y una reescritura, tejer referentes entre sus publicaciones anteriores y actuales, a la vez que hila y construye referentes con una de las figuras más emblemáticas de la poesía portuguesa que ya es, hoy en día, canónica (Florbela Espanca). A la vez, quiero mostrar cómo, así como Adília teje su poesía con referentes, yo también debo hacer lo mismo con mis notas: debo tejerlas entre ellas así como con los referentes de los que hablan.

\footnotetext{
${ }^{60}$ (N. del t.) La palabra en portugués "achadamente" es una invención de Adília. Según la poetisa, "achadamente" tiene que ver con lo cándido y caluroso de hacer el amor. En la revisión que hizo Adília a esta traducción, sugiró traducirla como "encontradamente" pero yo la traduzco como "halladamente", como sinónimo. Estos dos primeros versos son, además, una referencia a los dos primeros versos de la última estrofa del poema "perdidamente" de la poetisa portuguesa Florbela Espanca (1894-1930).
}

\section{$\cdot 129 \cdot$}

Figura 7: notas del traductor

Poema "[Yo quiero follar follar]", Escribir un poema es como atrapar un pez 
Pero tal vez aún no he respondido bien a mi pregunta de por qué anotar a Adília Lopes, una poeta contemporánea. Es verdad que podría presentar una traducción sin notas y el lector tendría que confiar necesariamente en mi criterio cuando al lee a Adília Lopes en un idioma que no es el de ella. Es decir, el lector, por falta de un espacio para el cuestionamiento sobre la traducción, tendría que confiar que, cuando lee mi traducción, lee la voz de Adília Lopes como sería en español. Y, no obstante, como traductor puedo darle a mi lector las herramientas para hacer de su lectura una cuestión más transparente, porque sé que el oficio de la traducción no es sólo el del traspaso de equivalentes lingüísticos. Quizá crea yo en una responsabilidad editorial del traductor frente a su texto, su oficio y su lector: el de develar y resaltar aquellas cuestiones del texto que facilitarían su lectura y su comprensión. Y no sería el primero en pensar esto. Ignacio Arellano, en su texto Edición crítica y anotación filológica en textos del Siglo de Oro. Notas muy sueltas (1990), ya había hecho una reflexión similar cuando afirmaba que

[U]n criterio aceptable [para el ejercicio de la anotación] puede ser, a mi juicio, este: se anotará todo aquello que creemos puede ofrecer dificultad al lector, y todo aquello que creemos contribuye a facilitar y enriquecer su percepción literal de la obra; es decir, dejamos fuera las valoraciones y ponderaciones y los análisis propiamente literarios, pero anotaremos tópicos, frases hechas, alusiones, fondo de motivos tradicionales sobre los que se construye un pasaje, léxico, etc. (Arellano 1990: 579)

Es decir, anotar un texto es crear un dispositivo para acercar ese texto al lector y para facilitar su lectura; un mecanismo para hacerlo lo más transparente que se pueda. Esto implica, pues, no sólo un ejercicio ecdótico entre el texto fuente y el texto traducido, sino también un análisis de lo que está dicho y, más aún, entredicho en el texto fuente (ídem: 580). Pero aún hay que ver que Arellano está hablando de textos que, por la distancia temporal que hay entre el Siglo de Oro y nosotros, necesitan las anotaciones para poderse leer. ${ }^{5}$ ¿Sería ese el caso de Adília Lopes, una poeta que sigue publicando hoy, en pleno 2019 ? Mi respuesta es que sí.

Primero, y siguiendo las ideas de Arellano cuando afirma que anotar no es una ciencia sino un arte (ídem: 579), el ejercicio de la anotación responde siempre a las necesidades que dictamina el texto que se tiene entre manos y que se trabaja. Con esto lo que digo es que un texto es el que le determina a su editor/traductor las maneras en que 
debe ser trabajado. En otras palabras, cuando me senté a traducir a Adília Lopes el texto mismo exigió sus notas. Esa "espontaneidad" de la que hablé en los primeros párrafos de esta sección, cuando traduje la primera vez a Adília y tuve que anotarla, surgió de las exigencias que el texto me hizo. Es decir, su espontaneidad fue sólo por no haber sido premeditada por mí, como sí lo sería en la segunda traducción que hago de Adília en $Z / S$. Pero surgió porque el texto lo pidió.

Hago esta afirmación porque tengo una certeza: cuando traduzco, rearmo. Y sigo aquí una reflexión que hacía en el aparato teórico que elaboré para acompañar la traducción de $Z / S$. La acción de traducir no es una acción que se haga siempre desde la plataforma sólida, prístina y diamantina del logos; la razón no siempre determina la manera de traducir. George Steiner le llama a eso los límites de una consciencia extraña o secundaria (según el idioma en que leamos su Después de Babel, si en español o en inglés). Y dice que es allí, en los límites de una consciencia extraña/secundaria donde sucede la traducción. Las palabras que él usa son: "[d]entro de los límites de una consciencia extraña [secondary], pero educada y momentáneamente exaltada, volvemos a rearmar paso a paso la obra del artista. Trazándola sobre el papel o siguiendo una vereda incierta, rastreamos la elaboración del poema" (Steiner 2013: 48). ${ }^{6}$ Esta noción de la consciencia extraña o secundaria, creo, va de la mano también con la noción de deriva que plantea Roland Barthes en El placer del texto. Allí, Barthes afirma que "[l]a deriva adviene cada vez que no respeto el todo, y que a fuerza de parecer arrastrado aquí y allá al capricho de las ilusiones, seducciones e intimidaciones de lenguaje como corcho sobre una ola, permanezco inmóvil haciendo eje sobre el goce intratable que me liga al texto (al mundo)" (Barthes 2011: 29). Si el oficio del traductor no sucede del todo desde la plataforma de la razón, es porque el traductor está, por fuerza, arrastrado aquí y allá por los caprichos del texto que traduce (como corcho sobre una ola) y es por eso, entre otras cuestiones como saberse "re-trazador" o "re-armador", que el traductor traduce "desde una consciencia extraña". Afirmo aquí que el traductor está subordinado al texto que traduce y no al revés. Por ende, tendría que seguir los caprichos que el texto le pide para poderse traducir; entre estos, la anotación.

Y es que, como he dicho ya varias veces y seguiré afirmando, la obra poética de Adília Lopes está hecha de una imbricación cuidadosa de referencias eruditas y cotidianas, de 
juegos lingüísticos y descripciones anecdóticas que configuran un universo discursivo y poético complejo. Traer a Adília Lopes al español - la tarea de traducir el universo adilianorequiere necesariamente, exige incluso, develar (dejar al descubierto) también ese archivo de curiosidades discursivas del que está hecho para que su lector hispanohablante pueda acceder (para usar las palabras de Arellano) al horizonte de recepción que puede tener un lector o un espectador portugués. Y no sólo un lector desprevenido, sino también uno juicioso, como los teóricos que se han dedicado a estudiarla, leerla e interpretarla. Y allí estaría una segunda razón para creer que la anotación es pertinente a la hora de trabajar a Adília Lopes: el texto pide la anotación porque el texto está lleno a reventar de material que merece ser anotado. Curiosamente, no obstante el potencial de este material, las nuestras serían las primeras ediciones de Adília Lopes que vienen acompañadas por notas.

Curiosamente, y para el caso de Escribir un poema es como atrapar un pez, cuando Tragaluz le envió un borrador preliminar a la mismísima Adília Lopes, una gran parte de las precisiones que hizo del borrador tuvieron que ver, justamente, con las notas que yo le había hecho a sus poemas traducidos. Es decir, además de corregir algunas cuestiones de traducción, Adília "pulió" unas notas que acompañaban los poemas, aprobó otras por feliz coincidencia y, así, entró en el mismo juego de anotación al que su obra me llevó a mí como traductor suyo. Sobre la nota 69 de la antología, que aparece mencionada antes (fig. 7), hay dedicado uno de los comentarios que hubo en este intercambio que tuvimos, y que presento a continuación (fig. 8 y fig. 9).

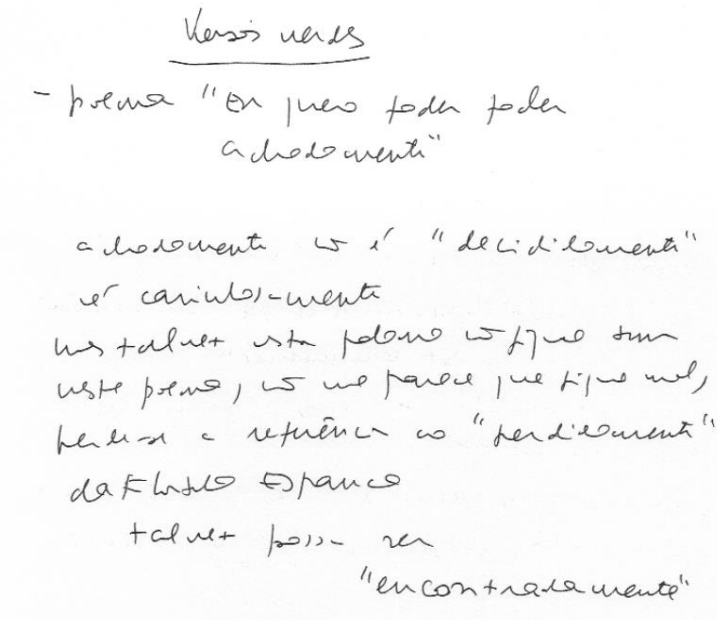

Figura 8: enmiendas de Adília Lopes a Escribir un poema es como atrapar un pez 
Sobre el poema "Eu quero foder foder"

\section{$\underline{\text { Versos verdes }}$}

- Poema "eu quero foder foder Achadamente"

achadamente não é "decididamente"

é canidosamente

mas talvez esta palavra não fique bem

neste poema, não me parece que fique mal, perderia a referencia ao "perdidamente"

da Florbela Espanca

talvez podia ser

"encontradamente".

Figura 9: transcripción de la enmienda de Adília Lopes (fig. 8)

Sobre el poema "Eu quero foder foder"

Concuerdo con Ignacio Arellano cuando alega que el oficio de la anotación no tiene una metodología científica objetiva; es más un arte, y uno subjetivo en tanto que está sujeto a quien la realiza. Arellano dice, exactamente, esto:

Más bien podríamos hablar de una poética de la anotación: la anotación filológica es, para mí, más que una «ciencia» objetiva aséptica, un «arte» que lleva en sí incorporada la actitud del anotador frente a su terea. Por no creo eso que se puedan determinar reglas exactas de cómo y cuánto anotar. (Arellano 1990: 579)

Cuando Arellano dice que el arte de la anotación lleva incorporada en sí la actitud del anotador es cuando (afirmo yo) dice que la anotación está su(b)jeta al sujeto que anota. Y, con esto, cabría pensar que ese sujeto que anota opera, de alguna manera, bajo la misma “consciencia extraña" con la que opera el traductor. Cuando Arellano separa la anotación de la ciencia está haciendo lo mismo que hacía yo unos renglones más arriba, separando la traducción del campo de la razón. Ninguna de las dos acciones sucede del todo en una plataforma positivista y logocéntrica. Sucederían, más bien, desde la consciencia extraña o secundaria de la que habla Steiner. Y más aún en este caso, cuando el traductor es el mismo 
personaje que anota, y anota porque (argumento yo) el texto que traduce se lo pide. Para volver a Adília, el texto que trabajo me lo pide porque esa poesía que traduzco está tan llena de referentes y de juegos, que para poder entregarle al lector un poema que esté en su horizonte de recepción (y que, por ende, le permita conectarse con él), requiere entonces de una o más notas que develen el tejido que arma al poema. En dichas notas quedan, pues, apuntalados los juegos y las referencias con los que Adília Lopes constituye sus poemas. Y será mejor decir: en dichas notas quedan apuntaladas las curiosidades discursivas con las que Adília arma sus poemas, y con las que Adília se constituye a sí misma como poeta y escritora.

\section{Parte II: Adília Lopes como síntesis discursiva de una erudición pop}

Ahora, cabe resolver esta cuestión que ya he mencionado antes, la de Adília Lopes como recurso de la escritora para con su escritura: como locus donde se junta o, mejor, se consolida un archivo de curiosidades discursivas, una interminable biblioteca de citas. Como ya he mencionado antes, Rosa Maria Martelo se ha interesado por entender la relación entre María José da Silva Viana Fidalgo de Oliveira (la persona de carne y hueso que escribe) y su pseudónimo literario, Adília Lopes. Su interés nos viene muy bien para intentar entender el uso de la figura escritural que surge de dicha relación. Y repito: en dos textos anteriores, Martelo ha propuesto que la relación que existe entre ambas es un "contrato autobiográfico" ("As armas desarmantes") y, luego, una relación dónde Adília Lopes es una suerte de "guante transparente" ("El guante y la mano"). Exploremos estas dos propuestas.

En su artículo "As armas desarmantes de Adília Lopes", Martelo argumenta que la relación que existe entre el pseudónimo literario Adília Lopes y su usuaria, Maria José, está mediada por una cuestión de "verdad poética" (Martelo 2010: 212), que, afirma Martelo, es una forma de vulnerarse y desnudarse a sí misma a la vez que se reviste con su poesía. Explico: cuando Martelo afirma que "Adília optou por mostrar o seu rosto, deixando que nele, directamente sobre ele, a solidão e o abandono se revelassem: '(um texto / é um rosto / um rosto / é um texto)', diz-nos um parênteses de Adília, noutro poema" (idem: 210), ${ }^{7}$ reconoce que la escritora hace una equivalencia entre la escritura - el poema - y su cuerpo su cara -; reconoce que no se cubre con, sino que se plasma (ella y su dolor) en el poema. 
Éste es un gesto particular porque no funciona simplemente a la manera de un espejo, el texto no es un mero reflejo suyo, sino que es un equivalente (un ser igual) hecho de palabras. Allí, Adília afirma: "este texto es mi rostro". Y hay que ver el primer verso del poema, en el que Adília dice "Soy, luego soy" (Lopes 2018: 114), una referencia a Descartes (cogito, ergo sum) y a la pregunta metafísica por la consciencia de ser. Si Descartes concluía que, a pesar de ser engañado por sus sentidos, él podía tener certeza de su existencia - de ser, de existir, por el hecho de pensar - en este poema, Adília Lopes sugiere que ella es, existe, porque está en el texto; ella es el texto. Martelo recuerda algo que ya he dicho varias veces: que varios de los poemas que Adília escribe y publica son autobiográficos, honestos (sufridos). Pero, además, Martelo recuerda que Adília confiesa su desconcierto cuando afirma, sin misterio, que lo que hace cuando escribe es "conviver: pôr a minha vida em comum" (Lopes apud Martelo 2010: 210). Este nivel de intimidad y de exposición de ella sólo puede justificarse, dice Martelo, en el hecho de que lo que escribe es verdad (Martelo 2010: 211), que así (le) pasó.

Para Martelo (en "As armas desarmantes") esta manera de exponerse tan crudamente en su poesía, a la vez que usa el nombre de Adília Lopes, se explica gracias a un contrato autobiográfico: será Adília, y no Maria José, quien escribirá la vida de la segunda y, así, será aquello que escribe. ${ }^{8} \mathrm{Y}$ aún habré de matizar más, porque luego Martelo afirmará que "[n]ão há poesia sem verdade, mas também não há verdade sem prosaísmo, diz-nos então Adília" (Martelo 2010: 213); la escritura adiliana (lo que Adília es) no está hecha con un lenguaje lírico y elevado: es prosaica. Y el lenguaje prosaico en Adília cumple una función específica: hablar desde lo cotidiano, ser cotidiana (idem: 211) o, como Adília misma afirmó, "ponerse en común". Martelo sentencia: "O contrato de leitura autobiográfica projectado pela poesia adiliana permite-Ihe construir uma imagem de poetisa que [escreve] a poesia de uma mulher biograficamente muito próxima dos padrões de uma vida vulgar, sem grande história, e a muitos níveis distante dos padrões convencionais do sucesso" (idem: 214). En otras palabras, este contrato le permite a la escritora constituir una figura escritural que será, a la vez, recurso retórico de su poesía "común", "cotidiana", lejana del éxito y la grandilocuencia y más bien cercana a la casa, a su cuarto y a sus gatos. ${ }^{9}$ 
Pero al contrato autobiográfico adiliano Martelo le sumará, más tarde, otra figura que también sirve para entender la función de Adília Lopes como nombre de la escritora. Rosa Martelo, en el coloquio internacional Por el barrio de Adília Lopes que tuvo lugar el 30 de abril de 2019 en la Universidad de los Andes, presentó una ponencia que ya he citado antes: "El guante y la mano (una historia de salvación)". Allí, propone que el contrato AdíliaMaria José es una unión "mucho más compleja que la habitual en casos de pseudonimia" (Martelo 2019: 2), que tendrá que transformarse constantemente; rehacer o reinventar el contrato.

En esta ocasión, Martelo se remonta a un poema del libro El escote de la dama de espadas (1988) para extraer de él una imagen: un guante que desviste una mano. ${ }^{10}$ No quiero hacer aquí una reconstrucción total del análisis de Martelo al poema, que es minucioso, pero quiero repetir de él las mismas cosas que resalta Martelo para rehacer o reformar el contrato autobiográfico: en el poema, la voz adiliana pide unos guantes que dejen en evidencia sus huellas digitales - "su identidad más fundamental y distintiva" (ídem: 4) - y sus manos heridas. Esa voz adiliana dice que no ve la necesidad de echarle talco a los dedos de los guantes para abrirlos, no hace falta, y cierra el poema afirmando, en español, que le gusta ver su propia sangre. En fin, la función de estos guantes particulares no es cubrir (esconder, proteger) sus manos sino dejarlas al descubierto, en evidencia. En palabras de Martelo, es adoptar "una segunda piel, en la que se inscriben las más auténticas huellas digitales" (ídem: 4); las huellas digitales de una mano herida.

Allí, en esa imagen del guante de piel que deja ver lo que cubre -incluso, cuya intención es dejar ver que no cubre, como anulando la acción principal del guante - y que además parece estar echa de la misma piel de la mano que quiere no-cubrir, es donde Martelo ubica la relación Adília-María José. Lo que antes llamaba una relación contractual, ahora se reconoce también bajo la forma de una literal "segunda piel", un guante que deja ver las heridas y las huellas de la mano, enmarcándolas, haciéndoles énfasis. Y no será gratuito mencionar que escribe usando el guante sobre la mano.

Algunas páginas más adelante, Martelo reconoce que Adília y Maria José parecen haber alcanzado una "simbiosis perfecta" en años más recientes (ídem: 11), sin que eso signifique necesariamente que Adília Lopes haya hecho desaparecer (o haya consumido) a 
Maria José da Silva Viana Fidalgo de Oliveira, o viceversa. Martelo cierra su disertación proponiendo que la relación entre ambas - el contrato autobiográfico entre el guante y la mano - es una oscilación metaléptica (ídem: 12): Maria José escribe a (hace nacer a) Adília y, luego, Adília escribe (narra, "poetiza") a Maria José. Casi como si Adília Lopes fuera el nombre para escribir y Maria José el nombre para vivir. Ambas, en el contrato que tienen, forman una dupla en la que necesitan la una de la otra. A esta dupla, Martelo la llama una "firma" (como una firma de abogados a la vez que una signatura): la Firma Adília \& Maria José. El contrato firmado que funda una firma.

Pero Adília misma, en el poema "Poesía y gestión" de $Z / S$, nos da más pistas para entender esta firma: Adília propone que Adília Lopes es una marca (como Apple). ${ }^{11}$ Y yo agrego: una marca hecha de escritura. Aquí no quiero proponer que sea más válido pensar en la dupla como "marca" que como "contrato" o como "guante-segunda piel". Propongo, más bien, que la poesía adiliana va transformando constantemente esta relación entre Adília y Maria José, y así mismo nos da pistas de cómo podemos leerla y entenderla en cada momento. Es decir, quiero reforzar la idea de que esta relación Adília-Maria José no es estática, pero apunta siempre a lo mismo independientemente de su estado: Adília es para el exterior de la escritora, Maria José para su interior y ambas son para sí. Y, en este caso, la marca Adília Lopes también nos puede esclarecer la cuestión de Adília Lopes como lugar catalítico de su poética a la vez erudita y a la vez común.

Hablemos un poco de "Poesía y gestión". Allí, Adília afirma: "Soy una empresaria exitosa. La marca Adília existe en el mercado desde 1984. Estamos en el 2016" (Lopes 2016: 74). ${ }^{12}$ Aquí Adília hace una reflexión sobre sí misma, sobre su nombre, y lo hace con un tono escéptico e irónico, ${ }^{13}$ pero ese tono justamente es el que le permite transformar su figura de poetisa (equiparándola además con Coco Chanel) para acomodarla a sus necesidades retóricas: "Existe la marca Adília como existe la marca Chanel. Perfumes y versos eficaces y eficientes" (ibídem). En efecto, sus necesidades retóricas, en este poema, tienen que ver con una burla crítica a la tendencia emprendedora que se ha tomado a las empresas, a la gente y a la vida en los últimos años, y ella (Adília) se inserta irónicamente en ese discurso: "[t]engo un nicho de mercado. [...] Soy un caso de emprendimiento" (ibídem). 
Insertarse allí, como ejemplo protagónico de su crítica-poema, es un gesto particular, pues vela, en esa crítica, otra cuestión: una verdad, como de las que hablaba Martelo; un ponerse en común. Aquí Adília revela que ha tenido que adaptarse constantemente al mundo para sobrevivir: "El ambiente siempre fue turbulento, mi aerodinamismo tuvo que ser mucho" (ibídem). ¿Y si leyéramos esto como otra forma de entender la dupla AdíliaMaria Jose? Adília, como nombre exterior, ha debido tener mucho "aerodinamismo", y esta palabra no es gratuita. La frase que le sigue a la cita anterior en el poema dice "Ahora que es la tormenta perfecta es la bonanza perfecta, dijo João Miguel Tavares" (ibídem), y luego cierra con una enumeración de términos entre los que están Zeitgeist (el espíritu de los tiempos) y Sturm und Drang (tormenta e ímpetu). Adília afirma haber tenido mucho aerodinamismo, porque "el ambiente ha sido turbulento", y el ambiente turbulento - una metáfora atmosférica - funciona aquí como símil de la vida, un equivalente a "los tiempos actuales". El espíritu o la esencia de los tiempos (Zeitgeist), parece decirnos Adília, es tormentoso y, ergo, le permite (o le impone) cierto impulso - ironía emprendedora - (Sturm und Drang) para adaptarse. Y así lo ha hecho.

Tener, pues, una capacidad para atravesar el viento, por fuerte que sea, se vuelve su propio triunfo emprendedor ("todo es cuestión de gestión", dice en el poema). Ahora en el 2016, Adília Lopes es marca, una que ha subsistido como subsiste Chanel aún incluso después de su muerte y con un perfume de conmemoración (como el Chanel No. 19) porque Adília ha sido aerodinámica. En fin, porque ha adaptado su figura escritural. Con esto quiero decir que la dupla Adília-Maria José se inventa y reinventa constantemente para adaptarse al "ambiente", pero esta (re)invención sucede siempre en el momento en que hay escritura, es decir, la dupla se reescribe.

Y aquí cabe recordar lo que afirma Roland Barthes, en "La muerte del autor" (1986) sobre el escritor moderno: "el escritor moderno nace a la vez que su texto" (Barthes 2012: 68). También recordemos lo que Adília había escrito en su poema "[Soy, luego soy]": "un texto | es un rostro | un rostro | es un texto" (Lopes 2018: 114). Adília como figura exterior (piel, guante, marca), como escritora, nace cada vez que escribe. Esta relación que hago aquí con el escritor moderno de Barthes no es gratuita. Recordemos que Barthes nos propone la posibilidad de que un texto sea (leal a la etimología de la palabra) un tejido ${ }^{14}$ hecho de otros 
textos: "un texto está formado por escrituras múltiples [...] que, unas con otras, establecen un diálogo, una parodia, una contestación" (Barthes 2012: 71). Este tejido se hace, para Barthes, en el lector, o mejor, el lector es quien teje cada texto; en el lector se recogen, se descifran, se posibilitan las escrituras múltiples. Esto se debe a que es el lector, como el espectador de las tragedias griegas, capaz de discernir "cada una de las palabras en su duplicidad, y además entiende [...] la sordera de los personajes que están hablando [frente] a él" (ibídem).

Hablemos un poco más sobre esta noción: en $S / Z$, el libro del que Adília sustrae el título de su poemario del 2016, Barthes afirmaba que “Ese 'yo' que se aproxima al texto es ya una pluralidad de otros textos, de códigos infinitos, o más exactamente perdidos (cuyo origen se pierde)" (Barthes 2011: 19). Aquí está la noción de que el lector (aquél que ejerce la acción de lectura) es un receptáculo previo de otras lecturas, una multiplicidad de textos, que se potencia y reproduce a través del acto/gesto de leer.

Pero habría que matizar esto aún más. Si antes hablábamos de la multiplicidad de textos que existe en el lector, habría aquí que hablar también de la multiplicidad misma que sucede en los textos que el lector tiene a bien leer. Barthes repite la noción de que el texto no debe fijarse o detenerse en un único sentido, que se hallaría gracias a una única lectura. Barthes afirma que leer no se trata de "detener la cadena de sistemas", de interrumpir el flujo de posibilidades de un texto. La lectura, dice, "Consiste en embargar esos sistemas no según su calidad finita sino según su pluralidad" (ídem: 20, énfasis mío). Con esto, Barthes parece reconocer que la "pluralidad" está tanto en el lector como en el texto: ambos se potencian y subsisten el uno gracias al otro; o mejor, ambos acontecen, toman sentido, en el acto de leer. El lector torna lector cuando lee. Y leer, afirma Barthes, es un trabajo en sí, un trabajo de lenguaje; es el oficio literario (ibídem).

Leer, o mejor dicho, el acto de lectura que propone Barthes, no debe ser una lectura pasiva, el lector no debe ser un receptáculo neutral que consume un texto sin saborearlo realmente. Al receptáculo neutral, este lector-consumidor, "no le queda más que la pobre libertad de recibir o rechazar el texto" (ídem: 14), mientras que el lector juicioso (¿el lector “barthiano"?), aquél que ejerce el oficio literario, es por sí mismo un "productor del texto" (ibídem). Y, en ese sentido, el trabajo literario, que comprende el oficio de la lectura y 
también el de la escritura, no fijaría al texto en una única interpretación cuando lo lee ni cuando lo escribe - como se fija una loza en una pared-, sino que lo abriría a la pluralidad de la que dicho texto está hecho (ídem: 15): lo produce más allá de un único sentido.

$Y$ se puede afirmar que Barthes hace una equiparación entre las actividades de lectura y escritura: el escritor es, básicamente, un lector que imprime sus lecturas en el texto que escribe. Esto es evidente cuando Barthes desmonta la noción del Autor (con a mayúscula) como génesis y significante único de un texto. Dado que es el lector, y no el Autor, el lugar en el que confluyen "todas las citas que constituyen una escritura" (Barthes 2012: 71), un texto obtiene su razón de ser en el lector y gracias al lector. Barthes hace aquí otra afirmación: "la unidad del texto no está en su origen [quien lo escribe], sino en su destino [quien lo lee]" (ibídem), que también indica que un texto se significa gracias al lector. Pero, a la vez, también quiere decir otra cosa: el origen de un texto, el escritor, no es en realidad su génesis. Es decir, el escritor no existe antes que su texto exista; nace a la vez que él, nace (torna escritor) en el momento en que escribe: "el escritor moderno nace a la vez que su texto; no está provisto en absoluto de un ser que preceda o exceda su escritura, no es en absoluto el sujeto cuyo predicado sería el libro; no existe otro tiempo que el de la enunciación, y todo texto está escrito eternamente aquí y ahora" (ídem: 68). El escritor no sería, pues, una figura genética sino un suceso de la escritura misma, del gesto de escribir. Y así, el escritor, igual que el lector, funcionaría como un espacio de confluencia de escrituras porque su gesto, escribir, es una imitación de un gesto anterior: es una citación (ídem: 69); citar, además, sólo sería posible después de leer. En ese sentido, esta confluencia de escrituras es una confluencia de citas, de lecturas previas que "habitan" en el escritor tanto como habitarían en el lector. El escritor es, ergo, un lector-que-escribe. Si el lector y el lector-que-escribe son un espacio de confluencia de textos, de una multiplicidad de textos plurales, significa que cuando un lector lee (cuando, al leer nace un lector), está poniendo en acción todos estos otros textos que carga consigo y, así, alimenta de posibilidad al texto que lee, permite un relacionamiento, un diálogo, un intercambio de sentidos entre textos - intertextos - y lo mismo sucede cuando escribe.

Lo que quiero proponer con esto es que Adília Lopes-Maria José da Silva es una escritora-lectora. El reconocimiento que hace Martelo habla de que la obra de Adília se 
asienta sobre un archivo de curiosidades discursivas es, quizás, el reconocimiento de que Adília escribe desde una biblioteca interminable de citas, à la Barthes: las citas que confluyen en la memoria de una lectora asidua. Cuando Adília Lopes torna marca, o torna firma, o contrato, o guante, es quizás un gesto de querer-tornar (querer-devenir), de manera constante, un escritor barthiano. Y esto se puede comprobar no sólo en cómo se concibe o se escribe ella en su poesía, sino también en cómo escribe esa poesía. Sus textos, a veces aforísticos, a veces tremendamente prosaicos, están escritos justamente con la consciencia de una lectora barthiana. La escritura de Adília es la de una persona que pone en sus textos el inmenso diccionario ya compuesto del que todo escritor está hecho (ídem: 70), como ya he propuesto, y que es todo aquello que ha leído. Su diccionario, las citas incontables de la cultura que lo componen, es la puesta en común de Adília en sus textos: su lenguaje prosaico cotidiano que la refiere a ella tanto como a la cultura popular y al conocimiento erudito. Esta escritora no escribe con la autoridad de un Autor romántico todopoderoso, sino con la crudeza de una escritura verdadera (nos da sus heridas, sus pasos, su vida) y también sus lecturas; escribe, pues, con la consciencia de un lector.

\section{NOTAS}

\footnotetext{
${ }^{1}$ Las citas que hago de Adília Lopes quedan en español referenciadas a la edición de 2018 de Tragaluz, pero en el texto cito el poemario portugués del que provienen.

${ }^{2}$ La antología recoge gran parte de su obra desde 1984 hasta 2014, y algunos poemas de su poemario del 2018, Estar em casa.

${ }^{3}$ c.f. Rosa Maria Martelo, El guante y la mano.

${ }^{4}$ La nota, además, referencia a la nota 63, que acompaña el poema del que extraigo el término "calcar".

${ }^{5}$ Arellano afirmará: “El objetivo ideal sería el de reconstruir el horizonte de recepción que podía tener un lector o un espectador, igualmente ideales, del XVII" (Arellano 1990: 579).
} 
${ }^{6}$ Steiner, en inglés, escribre "We retrace", "Volvemos a trazar", por lo que me tomo la libertad de cambiar el término en la cita, que origilamente decía "volvemos a realizar". Aquí la cita en inglés: "We re-enact, in the bounds of our own secondary but momentarily heightened, educated consciousness, the creation by the artist. We retrace, both in the image of a man drawing and of one following an uncertain path, the coming into form of the poem".

${ }^{7}$ El poema, sin título, pertenece al poemario A mulher-a-dias (2002) y, completo, dice: "Soy, luego soy I (un texto | es un rostro | un rostro | es un texto)" (Lopes 2018: 114).

${ }^{8}$ Explicaré más esta equivalencia entre la escritora y el texto cuando hable del poema "Poesía y gestión", en un par de páginas.

${ }^{9}$ Veremos, más adelante, que esta figura será también una de juego: esta mujer "vulgar" es, además, capaz de una gran erudición que sería más bien característica de una persona lejana de la vulgaridad.

${ }^{10}$ Transcribo aquí el poema, seguido de una traducción propia:

“Eu quero | um par de luvas | de que cor não sei | para desvestir as mãos | não pense que é para esconder as mãos | que quero desvestir as mãos | não tenho medo das impressões digitais | é para desvestir as mãos | é isso mesmo só isso | não vale a pena abrir os dedos das luvas | dedo a dedo | com a espátula de madeira | não vale a pena deitar pó | de talco dentro dos dedos | essas luvas servem | para desvestir as mãos? | deixe-me ver a sua mão | I| como tem a mão | como é que fez isso? | podia responder-Ihe assim | Me gusta ver la sangre!" (Lopes 2014: 121-122).

[“Yo quiero | un par de guantes | no sé de qué color | para desvestir las manos | no crea que es para esconder las manos | que quiero es desvestir las manos | no tengo miedo de las huellas digitales | es para desvestir las manos | es eso mismo sólo eso | ni vale la pena abrir los dedos de los guantes | dedo a dedo | con la espátula de madera | no vale la pena echar polvo | de talco dentro de los dedos | ¿esos guantes sirven | para desvestir las manos? | | | cómo tiene la mano | ¿cómo es que se hizo esto? | podría responderle así | iMe gusta ver la sangre!”].

${ }^{11}$ Martelo también reconoce, en este poema, la propuesta de marca Adília Lopes. Sin embargo, no se detiene tanto en la marca, sino que la utiliza como argumento para hablar de una constante acción de "doblar y zurcir" [dobrar e zurzir], (también de "desdobla" y de hilar-tejer) las palabras y sus posibilidades lingüísticas, un gesto característico de la escritura adiliana. Afirma que cuando Adília Lopes es una marca, aprovecha tener un nicho de mercado, para luego hablar de "nicho" en otra acepción: el espacio en una pared donde pueden ir figuras y decoraciones (Martelo 2019: 2).

12 Todas las citas de Z/S que hago quedan citadas a la edición de Averno de 2016, pero el texto es aquél traducido por mí y que saldrá publicado en 2020 por la editorial Puro Passaro.

${ }^{13}$ Sobre el carácter irónico y escéptico de Adília Lopes, leer “Adília Lopes, a ironista” de Rosa Maria Martelo y, así mismo, la definición sobre el ironista que expone Paul Rorty en Contingency, Irony, and Solidarity.

14 “[E]I texto es un tejido de citas provenientes de los mil focos de la cultura" (Barthes 2012: 69). 


\section{Bibliografía}

Almeida, Ana Bela (2016), Adilia Lopes, Imprensa da Universidade de Coimbra, Coimbra.

Arellano, Ignacio (1990), «Edición crítica y anotación filológica en textos del Silgo de Oro. Notas muy sueltas» in Crítica textual y anotación filológica en obras del Siglo de Oro, Editorial Castalia, Barcelona: 563-586.

Balderston, Daniel / Schwartz, Marcy E. comps. (2018). Voces en off. Traducción y literatura latinoamericana. Ediciones Uniandes, Bogotá.

Baltrusch, Burghard (2004), “Joder" etimológicamente -como "desentropiar" a Adília Lopes» in Poetas por su pueblo, Poesía Portuguesa, Zurgai, Bilbao: 104-111.

--(2008), «Adília Lopes: traducir entre la entropía y la subversión» in Lectora: revista de dones i textualitat, Barcelona: 231-249.

Barthes, Roland (2011), El placer del texto y Lección inaugural de la cátedra de Semiología Literaria del Collège de Frace, trads. Nicolás Rosa, Oscar Terán, Siglo veintiuno editores, CDMX.

-- (2012), "La muerte del autor" in El susurro del lenguaje, trad. Nicolás Rosa, Paidós, Barcelona: 65-72.

-- (2011), S/Z, trad. Nicolás Rosa, Siglo veintiuno editores, CDMX.

Benjamin, Walter (1971), «La tarea del traductor» in Angelus novus, Edhasa, Barcelona: 7583.

-- (1972), «Die Aufgaben des Übersetzers» in Gesammelte Schriften Vol. IV. Suhrkamp, Frankfurt am Main, 9-21.

Berman, Antoine (2014), La traducción y la letra o el albergue de lo lejano, Dedalus editores, Buenos Aires.

Cattaneo, Carlo Vittorio (1998), Presentación de El poeta de Ponchichéry. Lopes, Adilia, trad. Mario Morales Castro, Trilce ediciones, CDMX.

Espanca, Florbela (2009), Obra poética, vol I, Editorial Presença, Lisboa. 
-- (2009), Obra poética, vol II, Editorial Presença, Lisboa.

Evangelista, Lúcia Liberato (2011), Vida em comum. A poética de Adília Lopes, Universidad de Oporto, tesis doctoral.

García, Cristina (2018), "La traducción como restauración». Voces en off. Traducción y literatura latinoamericana. Daniel Balderston / Marcy E. Schwartz (comps.), Ediciones Uniandes, Bogotá.

Giraldo Gil, Alejandro (2018), «Desentropiar las cucarachas» in Escribir un poema es como atrapar un pez. Lopes, Adília. Trad. Alejandro Giraldo Gil. Tragaluz editores, Medellín.

Hampe, Michael / Renz, Ursula. Schnepf, Robert (eds.) (2011), Spinoza's Ethics. Brill, Boston. Ladeira, António (2007), «Gênero, Perversão e Subversão em Clarice Lispector e Adília Lopes» in Revista LitCult, vol 6, Universidad de Almería, Almería: 2-15

Leal, Filipa (2014), Adília Lopes Lopes, Não edições, Lisboa.

-- (2005), Aspectos do Cómico na Poesia de Alexandre O'Neill, Adília Lopes e Jorge de Sousa Braga, Universidade do Porto, tesis de maestría.

-- (2018), «Creo más en la existencia de Dios que en la de Ella» in Escribir un poema es como atrapar un pez. Lopes, Adília, trad. Alejandro Giraldo Gil, Tragaluz editores, Medellín.

Lopes, Adília (2014), Dobra, Assírio \& Alvim, Lisboa.

-- (1998), El poeta de Pondichéry, trad. Mario Morales Castro, Trilce ediciones, CDMX.

-- (2018), Escribir un poema es como atrapar un pez, trad. Alejandro Giraldo Gil, Tragaluz editores, Medellín.

-- (2016), Z/S, Averno, Lisboa.

Maffei, Luis (2019), «Camões em Adília Lopes» in Forma breve: 337-344.

Martelo, Rosa Maria (2004), «Adília Lopes - ironista», Scripta, vol. 8, no. 15, Revista do Programa de Pós-graduação em Letras e do Centro de Estudos Luso-afro-brasileiros. PUC de Minas Gerais: 106-116. 
-- (2010), «As Armas Desarmantes de Adília Lopes», in Didaskalia, Vol XL. Faculdad de Teología de la Universidad Católica Portuguesa, Oporto: 207 - 222.

-- (2019), «El guante y la mano» presentado en Por el barrio de Adília Lopes. Coloquio internacional, Universidad de los Andes, Bogotá: 30 de abril de 2019.

Melo, Sónia Rita Cardoso (2013), «Adília Lopes ou a impessoalidade da terceira mulher», in Ex æquo, no. 27, Associação Portuguesa de Estudos sobre Mulheres, Lisboa: 129-141.

-- (2012), «Dentro da torre: identidade e "escrita femenina" em Adília Lopes» in Moderna språk, vol. 106, no. 2, Universidad de Gutemberg - Institutionen för moderna språk, Upsala.

-- (2015), Des-Dobra: re-visão e tradução. A construção da poetisa em Adília Lopes, Universitat de Barcelona, tesis doctoral.

Paz, Octavio (1990), Traducción: literatura y literalidad, Tusquets, Barcelona.

Pedrosa, Celia (2011), Ensaios sobre poesia e contemporaneidade, Editora da Universidade Federal Fluminense, Niterói.

-- (2007), «Releituras da tradição na poesía de Adília Lopes», in Via Atlântica, no 11, junio: 87-01.

Piglia, Ricardo (2018), «Escritura y traducción». Voces en off. Traducción y literatura latinoamericana. Daniel Balderston, Marcy E. Schwartz (comps.), Ediciones Uniandes, Bogotá: 3-15.

Pinheiro, Paula Moura (2002), "Adília Lopes. O estranho mundo de Maria José», in 27/8. Dom Quixote, Alfragide: 181-205

Rorty, Paul (2007), Contingency, Irony, and Solidarity, Cambridge University Press, Ciudad de Nueva York.

Sales, Paulo Alberto da Silva (2017), «O jogo poético de Adília Lopes: o pastiche na criação do sentir lírico», in Revista Desassossego, no. 17, Universidade de São Paulo: 144-163.

Sousa, Phabulo Mendes (2014), A tesitura poética de Adília Lopes, Universidad de São Paulo, tesis doctoral. 
Steiner, George (1976), After Babel. Aspects of Language and Translation, Oxford University Press, Ciudad de Nueva York.

-- (2013), Después de Babel, trad. Adolfo Castañón, Fondo de Cultura Económica, CDMX.

Warburton, Nigel (2008), Philosophy: The Classics, Routledge (Taylor \& Francis Group), Ciudad de Nueva York.

Alejandro Giraldo Gil es egresado de la Universidad de los Andes (2015) de los programas de Literatura (Literato) y Arte (Maestro en Arte). Como traductor y editor ha trabajado junto al profesor Pizarro en la reedición del texto Orpheu 1915-1965 de José de Almada Negreiros, y la traducción de parte de la obra poética de Adília Lopes, que se publicó como la antología Escribir un poema es como atrapar un pez en noviembre de 2018. Trabaja actualmente como traductor, corrector de estilo y gestor de investigación del Centro de Investigación y Creación (CIC) de la Universidad de los Andes, donde, entre otras funciones, es el editor de la Gaceta CIC. 